\title{
\begin{tabular}{l|l} 
Mitraries & DSpace@MIT
\end{tabular}
}

\author{
MIT Open Access Articles
}

\section{Stormtime observations of the flux of plasmaspheric ions to the dayside cusp/magnetopause}

The MIT Faculty has made this article openly available. Please share how this access benefits you. Your story matters.

Citation: Foster, J. C. “Stormtime Observations of the Flux of Plasmaspheric lons to the Dayside Cusp/magnetopause." Geophysical Research Letters 31, 8 (2004): L08809 (c) 2004 American Geophysical Union

As Published: http://dx.doi.org/10.1029/2004GL020082

Publisher: American Geophysical Union (AGU)

Persistent URL: http://hdl.handle.net/1721.1/114699

Version: Final published version: final published article, as it appeared in a journal, conference proceedings, or other formally published context

Terms of Use: Article is made available in accordance with the publisher's policy and may be subject to US copyright law. Please refer to the publisher's site for terms of use. 


\title{
Stormtime observations of the flux of plasmaspheric ions to the dayside cusp/magnetopause
}

\author{
J. C. Foster, ${ }^{1}$ A. J. Coster, ${ }^{1}$ P. J. Erickson, ${ }^{1}$ F. J. Rich, ${ }^{2}$ and B. R. Sandel ${ }^{3}$ \\ Received 25 March 2004; accepted 30 March 2004; published 23 April 2004.
}

[1] For the large geomagnetic disturbance on April 11, 2001, we combine data from the Millstone Hill radar, a network of GPS TEC receivers, and the DMSP F-12 and IMAGE satellites, to estimate the sunward flux of thermal plasma associated with erosion of the outer plasmasphere/ ionosphere in the dusk sector. Direct radar observations of the $\mathbf{E} \times \mathbf{B}$ advection of SED plasma determine a flux of $>10 \mathrm{E} 26$ ions/s to the noontime cusp at $F$-region heights. DMSP in situ observations provide a similar estimate. Assuming a dipolar magnetic field, we project our low-altitude observations into the outer plasmasphere, obtaining a total sunward flux of $>10 \mathrm{E} 27$ ions/s. High-altitude IMAGE EUV observations of the plasmasphere drainage plume provides an estimate of $1.5 \times$ $10 \mathrm{E} 27 \mathrm{ions} / \mathrm{s}$ for the sunward flux. Such rates of sunward plasma transport are sufficient to deplete a 1-Re shell of the outer plasmasphere in $\sim 1$ hour. INDEX TERMS: 2730 Magnetospheric Physics: Magnetosphere-inner; 2740 Magnetospheric Physics: Magnetospheric configuration and dynamics; 2760 Magnetospheric Physics: Plasma convection; 2768 Magnetospheric Physics: Plasmasphere; 2788 Magnetospheric Physics: Storms and substorms. Citation: Foster, J. C., A. J. Coster, P. J. Erickson, F. J. Rich, and B. R. Sandel (2004), Stormtime observations of the flux of plasmaspheric ions to the dayside cusp/magnetopause, Geophys. Res. Lett., 31, L08809, doi:10.1029/2004GL020082.

\section{Introduction}

[2] Carpenter (unpublished communication, 2003) has coined the term plasmasphere boundary layer (PBL) to describe the region of dynamic interaction between the plasmas of the inner and outer magnetosphere at the outer extent of the plasmasphere. The MIT Millstone Hill incoherent scatter radar, located at $55^{\circ} \Lambda$ (invariant latitude) near the ionospheric projection of the plasmapause and the PBL, regularly observes storm enhanced density (SED) in the pre-midnight sub-auroral ionosphere during the early stages of magnetic storms [Foster, 1993]. These high-TEC (total electron content) patches and plumes of ionization appear near dusk at the equatorward edge of the main ionospheric trough and stream sunward carried by the low-latitude edge of the sub-auroral disturbance

\footnotetext{
${ }^{1}$ MIT Haystack Observatory, Westford, Massachusetts, USA.

${ }^{2}$ Air Force Research Laboratory, Hanscom Air Force Base, Massachusetts, USA.

${ }^{3}$ Lunar and Planetary Laboratory, University of Arizona, Tucson, Arizona, USA.
}

Copyright 2004 by the American Geophysical Union. 0094-8276/04/2004GL020082 electric field. Recent observations using both ground and space-based thermal plasma imaging techniques have revealed such an ionospheric SED event to be the lowaltitude signature of the plasmaspheric drainage plume which resulted from the erosion of the PBL [Foster et al., 2002]. In this report, we use direct observations of the sunward $\mathbf{E} \times \mathbf{B}$ advection of the SED plasma in the ionospheric projection of such a plasmaspheric drainage plume to determine the flux of ions to the noontime cusp at $F$-region heights and, by inference, the flux of plasmaspheric ions out of the PBL and towards the dayside magnetopause. We combine ground-based radar and GPS TEC observations with in situ and remote measurements made with the DMSP and IMAGE satellites to provide three estimates of the thermal ion flux carried into the noon sector during the strong disturbance $(\mathrm{Kp}=9)$ on April 11, 2001.

\section{Observations}

\subsection{GPS TEC Maps of Plasmasphere Erosion}

[3] The satellites of the GPS constellation are in 12-hr circular orbits $(\sim 20,000-\mathrm{km}$ altitude $)$ with orbital inclination $\sim 55^{\circ}$. The GPS satellites have apogee near $20,000 \mathrm{~km}$ ( $\mathrm{L} \sim 4$ ) and the vertical TEC determined is the combined contribution of the ionosphere and overlying plasmasphere. For the severe disturbance event of April 11, 2001, we have determined 2-D maps of vertical TEC from $\sim 120$ North American GPS sites. Figure 1 presents such a map showing an intense SED plume with $>100$ TECu extending NW toward the noontime cusp from a mid-latitude source over the SE US mainland. (Local time along the US east coast is $\sim 14$ LT). For a similar event, Foster et al. [2002] demonstrated a one to one mapping between the low-altitude highdensity features and a plasmaspheric drainage plume seen from space by the IMAGE EUV instrument. Assuming that this relationship holds in general, the SED and enhanced TEC features are signatures of the erosion of the dusk-sector plasmasphere by strong inner-magnetosphere SAPS (sub auroral polarization stream) electric fields [Foster and Burke, 2002].

[4] In Figure 2 we have used the Tsyganenko [2002] magnetic field model to project the features of Figure 1 into the magnetosphere equatorial plane. The SED plume maps into a broad drainage plume reaching sunward from the greatly eroded plasmapause position near $\mathrm{L}=2$ to the dayside magnetopause near noon. Mapping to high latitudes along a model magnetic field in such disturbed conditions (Kp 9) is not perfect. At ionospheric heights, the plume of SED extends continuously from a low-latitude source to flux tubes which intersect the dayside magnetopause. Direct observations of sunward-streaming plasmaspheric material 


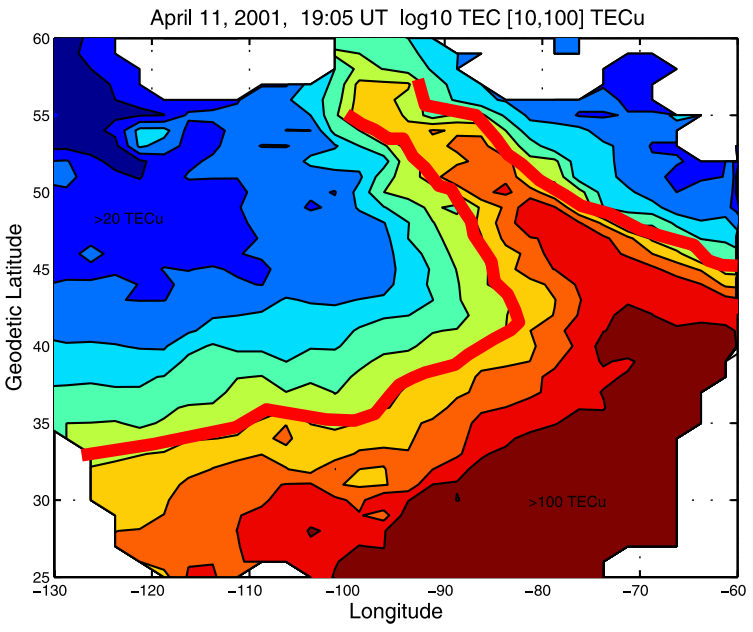

Figure 1. A map of Total Electron Content (TEC) derived from GPS observations reveals the strong plume of storm enhanced density (SED) spanning North America. Heavy lines mark the $>70 \mathrm{TECu}$ contours which outline the extent of the plume at this time.

at the equatorial, post-noon magnetopause have been reported by Chandler and Moore [2003], and on recently opened magnetic field lines in the high-latitude magnetosheath by Su et al. [2001b].

\subsection{IS Radar Observations of Plasma Flux}

[5] On April 11, 2001, the Millstone Hill incoherent scatter radar performed low-elevation angle azimuth scans which directly observe both plasma density and line of sight velocity at altitudes $150 \mathrm{~km}-850 \mathrm{~km}$, spanning the disturbed $F$ region across the SED plume. The product of density and velocity quantifies the sunward ion flux in the topside $F$ region, while GPS TEC observes the total content within the streaming plume out to an altitude of 4 earth radii $(\mathrm{Re})$. Comparisons of $F$-region TEC determined from the radar observations with simultaneous GPS TEC measurements indicates that $40 \%-50 \%$ of the total vertical TEC lies above $850 \mathrm{~km}$ altitude [Coster et al., 2003].

[6] Figure 3 presents a radar scan map of sunward plasma flux at $F$ region heights at the time of the TEC map of Figure 1. The observed characteristics of this event are similar to that reported by Foster et al. [2002], and for both events a region of strong $\left(>10^{15} \mathrm{~m}^{-2} \mathrm{~s}^{-1}\right) F$-region sunward flux was coincident with the high-TEC region of the drainage plume. We calculate $\sim 2.5 \times 10^{26}$ ions $\mathrm{s}^{-1}$ for the total flux in the $F$ region (below $1000 \mathrm{~km}$ ) by integrating the direct Millstone Hill observations [average sunward velocity: $800 \mathrm{~m} / \mathrm{s}$; average $F$-region density $10^{12} \mathrm{~m}^{-3}$; latitude width: $\sim 5$ degrees $(600 \mathrm{~km})$; altitude extent $\sim 500 \mathrm{~km}]$. A similar estimate is obtained using the GPS TEC observations through the plume region. These indicate $\sim 90 \mathrm{TECu}$ integrated total content, of which $\sim 50 \%-60 \%$ $(50 \mathrm{TECu})$ lies in the $F$ region below $1000 \mathrm{~km}$ altitude. Combining the GPS value of $F$-region TEC and spatial extent $\left(\sim 5^{\circ}\right)$ with the radar determination of the sunward velocity also indicates that $>10^{26}$ ions/s are streaming from the dusk PBL to the noontime cusp. Our studies of such strong erosion events indicate a duration of 5 or more hours, indicating a total transfer of $\sim 10^{30}$ ions to the $F$-region

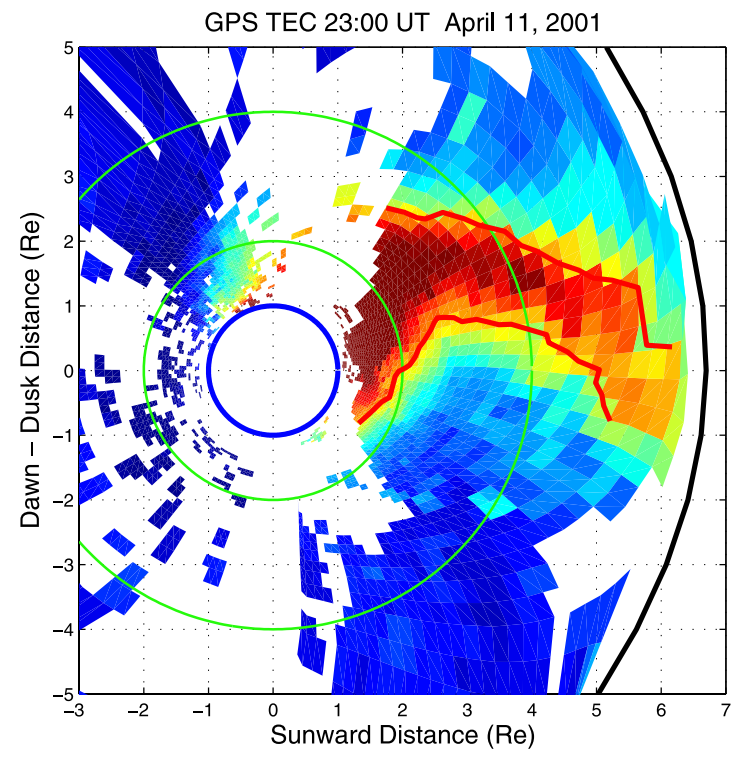

Figure 2. Tsyganenko magnetic field aligned mapping is used to project the GPS TEC observations of Figure 1 from their $350-\mathrm{km}$ altitude ionospheric penetration points into the magnetospheric equatorial plane. A broad drainage plume of plasmaspheric material extends sunward from a greatly eroded plasmapause position near $\mathrm{L}=2$ to the dayside magnetopause near noon.

cusp/acceleration region in a large plasmasphere/ionospheric erosion event.

\subsection{IMAGE EUV Observations of the Plasmaspheric Plume}

[7] IMAGE EUV images using resonantly-scattered sunlight from plasmaspheric helium depict the structure and evolution of the PBL and the plasmapause across wide swaths of MLT [Sandel et al., 2001]. This instrument is sensitive to features where the equatorial $\mathrm{He}+$ abundance exceeds $40 \mathrm{~cm}^{-3}$ [Goldstein et al., 2003b]. EUV imagery did not begin until after the peak of the April 11, 2001 erosion event, and the image shown in Figure 4 depicts the

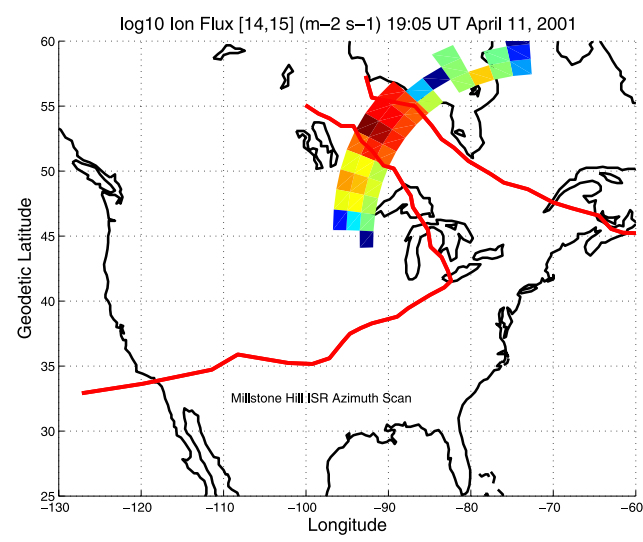

Figure 3. The Millstone Hill radar scan map of sunward plasma flux at $F$ region heights is presented for the time of TEC map of Figure 1. Heavy lines indicating the GPS TEC $>70$ TECu boundaries at the edges of the SED plume have been drawn on Figure 1 and these plume boundaries have been transferred to Figure 3. 


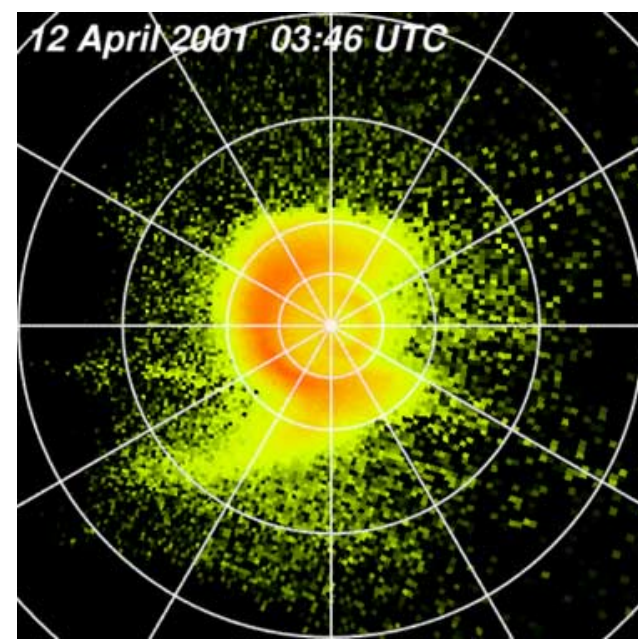

Figure 4. IMAGE EUV observations of resonantlyscattered sunlight from plasmaspheric helium are shown mapped to the magnetic equatorial plane. The azimuthal coordinate is MLT, with midnight at the right. The white circles are at $\mathrm{L}=1,2,4$, and 6 . A prominent drainage plume extends from the plasmasphere at roughly 17 MLT to at least $\mathrm{L}=5$ near 15 MLT.

residual plasma plume observed for several hours following the interval of intense erosion shown in Figure 1.

[8] The EUV image in Figure 4 has been mapped to the plane of the magnetic equator using the method described by Sandel et al. [2003]. The plasmapause is inside $\mathrm{L}=2.5$ at most local times. A prominent drainage plume extends from the plasmasphere at roughly 17 MLT to at least $\mathrm{L}=5$ near 15 MLT. A brightness profile across the drainage plume near its base shows a peak column abundance of $7.5 \times 10^{15} \mathrm{He}+$ $\mathrm{m}^{-2}$ and a FWHM of about 0.6 Re. If the flow velocity is $5 \mathrm{~km} / \mathrm{s}$, then the flow rate down the plume is roughly $1.5 \times$ $10^{26} \mathrm{He}+/ \mathrm{sec}$. If $\mathrm{He}+$ accounts for $10 \%$ of the plasma, then the inferred ion flow rate is $1.5 \times 10^{27} / \mathrm{sec}$, in close agreement with our estimate of the high-altitude flux derived from the ground-based observations, discussed below.

\subsection{DMSP Observations of Plasma Flux}

[9] The DMSP F12 satellite, in a sun-synchronous dawndusk orbit at $\sim 900 \mathrm{~km}$ altitude, flew poleward across the dusk-sector source of the strong TEC plume shown in Figure 1. In situ measurements of sunward ion flux determined from ion velocity and density are shown in Figure 5. In the dusk sector, a region of strong subauroral sunward convection (bottom) overlaps the PBL and the equatorward edge of the ionospheric trough (middle). Sunward ion flux at $880 \mathrm{~km}$ altitude (top) was $\sim 5 \times 10^{13}$ ions $\mathrm{m}^{-2} \mathrm{~s}^{-1}$ and spanned $\sim 6$ deg of latitude. Using the fact that the density at $900 \mathrm{~km}$ is $\sim 10$ times less than at the $F$-region peak, and integrating from $200 \mathrm{~km}$ to $1000 \mathrm{~km}$ altitude, yields an estimate of $\sim 10^{26}$ ions/s for the $F$-region sunward flux.

\section{Estimate of Total Flux to the Dayside Magnetopause}

[10] Radar observations of SED reported by Foster [1993] have been projected into the equatorial plane by Su et al. [2001a] and compared with geosynchronous orbit observations of a sunward-streaming plume of plasmaspheric material. That study concluded that the eroded plasmaspheric/ionospheric material is extended along the magnetic field and that SED is an ionospheric signature of the erosion of the outer plasmasphere. We estimate the total sunward ion flux in a strong erosion event by projecting ionospheric observations made near the base of the plume into the high-altitude PBL $(\mathrm{L} \sim 3.5)$ with the assumptions of dipolar magnetic field, no parallel electric fields.

[11] The motion of the thermal plasmas is controlled by the electric field (E), and in the absence of parallel electric fields, E maps between the ionosphere and high altitudes along the magnetic field. A dipole magnetic field, $\mathrm{B}$, has $\mathrm{r}^{-3}$ dependence on geocentric distance. Mozer [1970] described the scaling rules of the electric field between the ionosphere and magnetic equator in a dipole field. Azimuthal components scale upward as $\mathrm{L}^{-3 / 2}$, while meriodional E-field components scale upward as $0.5 \mathrm{~L}^{-1}(\mathrm{~L}-3 / 4)^{-1 / 2}$. A characteristic sunward velocity for ionospheric SED is $800 \mathrm{~m} / \mathrm{s}$ [Foster, 1993], and for the April 11, 2001 event direct measurements made by the radar and DMSP in the region of SAPS/PBL overlap range from $500 \mathrm{~m} / \mathrm{s}$ to $1200 \mathrm{~m} / \mathrm{s}$. The plasma convection velocity, $\mathrm{v}=\left[\mathbf{E} \times \mathbf{B} / \mathrm{B}^{2}\right]$ scales as $\mathrm{E} / \mathrm{B}$, and we estimate streaming velocities of $3 \mathrm{~km} / \mathrm{s}$ to $8 \mathrm{~km} / \mathrm{s}$ for the high-altitude material in the drainage plume at the outer edge of the PBL near $r=3.5$ Re.

[12] Both the volume and characteristics of the sunward-streaming drainage flux tubes at plasmaspheric heights $(>1000 \mathrm{~km})$ are dominated by their near-equatorial values. We approximate the density of the high-altitude region by the equatorial saturation density at $\mathrm{L} \sim 4,5 \times$ $10^{8} \mathrm{~m}^{-3}$, derived from in situ observations [e.g., Carpenter and Anderson, 1992; Sheeley et al., 2001]. The volume of a dipole flux tube at $\mathrm{L}=4$ is $10^{9} \mathrm{~m}^{3}$ (per $\mathrm{m}^{2}$ at $1000-\mathrm{km}$ altitude) [Carpenter and Park, 1973]. The SED plume at ionospheric heights spanned $5^{\circ}$ latitude $(\sim 1 \mathrm{Re}$ of $\mathrm{L}$

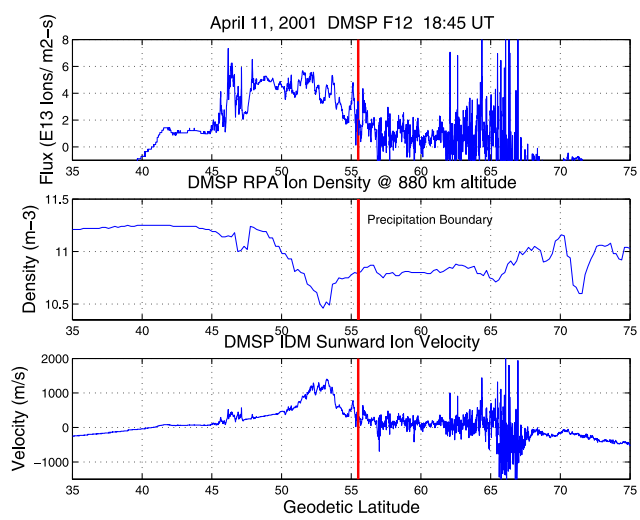

Figure 5. Sunward ion flux has been determined from in situ measurements of ion velocity and density by the DMSP F12 satellite at $0^{\circ} \mathrm{E}$ longitude (19 LT). F12 flew poleward across the base of the TEC plume of Figure 1 near dusk, where the subauroral polarization stream (bottom) overlaps the plasmasphere boundary layer and the equatorward edge of the ionospheric trough (middle). Sunward ion flux of $\sim 5 \times 10^{13}$ ions $\mathrm{m}^{-2} \mathrm{~s}^{-1}$ (at $880 \mathrm{~km}$ altitude) spanned $\sim 6$ degrees of latitude. 
space; $\sim 6 \times 10^{5} \mathrm{~m}$ ), making the total volume of a 1meter N-S cross section of the high-altitude plume $\sim 6 \times$ $10^{14} \mathrm{~m}^{3}$. Multiplying this by the mean density $(5 \times$ $\left.10^{8} \mathrm{~m}^{-3}\right)$ and velocity $(5 \mathrm{~km} / \mathrm{s})$, our estimate the sunward flux of thermal ions away from the dusk PBL during a severe disturbance is $1.5 \times 10^{27}$ ions/s. Matsui et al. [1999] report $>60 \%$ occurrence frequency for sunwardstreaming fluxes of cold dense plasma at $\mathrm{L} \sim 10$ at 14 MLT, and estimate $3 \times 10^{25}$ ions/s for the sunward flux.

\section{Discussion}

[13] This analysis of the April 11, 2001 event indicates that at $F$-region heights a plume of storm enhanced density stretched continuously from the ionospheric projection of the dusk plasmapause to the dayside cusp. Separate calculations using observations from the Millstone Hill radar, DMSP overflights, and ground-based GPS TEC indicate that the SED plume carried a flux of $>10^{26}$ ions/s into the cusp ionosphere during the peak of the event. At magnetospheric heights, we calculate that this plasmasphere drainage plume transported a flux of $>10^{27}$ ions/s to the dayside magnetopause. Elphic et al. [1997] have estimated the flux of plasmaspheric ions which are injected into the magnetotail and convected up and over the polar cap during strong disturbances to be $\sim 10^{26}$ ions/s, comparable to the flux we report here. Foster and Doupnik [1984] observed the lowlatitude SED plasma streaming poleward through the cusp ionosphere using the Chatanika incoherent scatter radar, and Foster [1989] has described the role of the SED material as a source of topside $F$-region density plumes and patches observed at polar cap latitudes.

[14] Finally, we use our estimate of the PBL drainage flux to determine whether erosion of the PBL by the SAPS electric field constitutes a mechanism sufficient to account for the loss of material seen in severe events. The volume of a dipolar shell of the PBL extending from $\mathrm{L}=3$ to $\mathrm{L}=4$ is $\sim 10^{22} \mathrm{~m}^{3}$. Using our estimate of mean density $(5 \times$ $10^{8} \mathrm{~m}^{-3}$ ), we find the integrated content of a 1-Re shell of the PBL to be $\sim 5 \times 10^{30}$ ions. For a sunward drainage flux of $\sim 1.5 \times 10^{27}$ ions $/ \mathrm{s}$, we estimate $\sim 50 \mathrm{~min}$ for the time needed to erode a 1-Re shell of the PBL, in keeping with observations of the rate of erosion of the plasmapause determined by IMAGE EUV. [e.g., Goldstein et al., 2003a].

[15] Acknowledgments. GPS and IMAGE analysis are supported by NASA SEC Guest Investigator Award (NAG5-12875) to the MIT Haystack Observatory. Radar observations and analysis at the Millstone Hill Observatory are supported by Co-operative Agreement ATM-0233230 between the National Science Foundation and the Massachusetts Institute of Technology. Work at The University of Arizona was funded by a subcontract from Southwest Research Institute, under NASA contract NAS5-96020 with SwRI. DMSP analysis is partially sponsored by the Air Force under
Air Force Contract AF19628-00-C-0002. We thank W. Rideout for automating the GPS processing and the Tsyganenko mapping routines.

\section{References}

Carpenter, D. L., and R. R. Anderson (1992), An ISEE/whistler model of equatorial electron density in the magnetosphere, J. Geophys. Res., 97, 1097.

Carpenter, D. L., and C. G. Park (1973), On what ionospheric workers should know about the plasmapause-plasmasphere, Rev. Geophys., 11, 133

Chandler, M. O., and T. E. Moore (2003), Observations of the geopause at the equatorial magnetopause: Density and temperature, Geophys. Res. Lett., 30(16), 1869, doi:10.1029/2003GL017611.

Coster, A. J., J. Foster, and P. Erickson (2003), Monitoring the Ionosphere with GPS: Space weather, GPS World, 14, 42.

Elphic, R. C., M. F. Thomsen, and J. E. Borovsky (1997), The fate of the outer plasmasphere, Geophys. Res. Lett., 24, 365.

Foster, J. C. (1989), Plasma transport through the dayside cleft: A source of ionization patches in the polar cap, in Electromagnetic Coupling in the Polar Clefts and Caps, edited by P. Sandholt and A. Egeland, pp. 343354, Kluwer Acad., Norwell, Mass.

Foster, J. C. (1993), Storm-time plasma transport at middle and high latitudes, J. Geophys. Res., 98, 1675

Foster, J. C., and W. J. Burke (2002), SAPS: A new characterization for sub-auroral electric fields, Eos Trans. $A G U, 83,393$.

Foster, J. C., and J. R. Doupnik (1984), Plasma convection in the vicinity of the dayside cleft, J. Geophys. Res., 89, 9107.

Foster, J. C., A. J. Coster, P. J. Erickson, J. Goldstein, and F. J. Rich (2002), Ionospheric signatures of plasmaspheric tails, Geophys. Res. Lett., 29(13), 1623, doi:10.1029/2002GL015067

Goldstein, J., B. R. Sandel, W. T. Forrester, and P. H. Reiff (2003a), IMFdriven plasmasphere erosion of 10 July 2000, Geophys. Res. Lett., 30(3), 1146, doi:10.1029/2002GL016478.

Goldstein, J., M. Spasojevic, P. H. Reiff, B. R. Sandel, W. T. Forrester, D. L. Gallagher, and B. W. Reinisch (2003b), Identifying the Plasmapause in IMAGE EUV data using IMAGE RPI in situ steep density gradients, J. Geophys. Res., 108(A4), 1147, doi:10.1029/2002JA009475.

Matsui, H., T. Mukai, S. Ohtani, K. Hayashi, R. C. Elphic, M. F. Thomsen, and H. Matsumoto (1999), Cold dense plasma in the outer plasmasphere, J. Geophys. Res., 104, 25,077.

Mozer, F. S. (1970), Electric field mapping in the ionosphere at the equatorial plane, Planet. Space Sci., 18, 259.

Sandel, B. R., R. A. King, W. T. Forrester, D. L. Gallagher, A. L. Broadfoot, and C. C. Curtis (2001), Initial results from the IMAGE extreme ultraviolet imager, Geophys. Res. Lett., 28, 1439.

Sandel, B. R., J. Goldstein, D. L. Gallagher, and M. Spasojevic (2003), Extreme ultraviolet imager observations of the structure and dynamics of the plasmasphere, Space Sci. Rev., 109, 25.

Sheeley, B. W., M. B. Moldwin, H. K. Rasool, and R. R. Anderson (2001), An empirical plasmasphere and trough density model: CRRES observations, J. Geophys. Res., 106, 25,631.

Su, Y.-J., M. F. Thomsen, J. E. Borovsky, and J. C. Foster (2001a), A linkage between polar patches and plasmaspheric drainage plumes, Geophys. Res. Lett., 28, 111.

Su, Y.-J., J. E. Borovsky, M. F. Thomsen, N. Dubouloz, M. O. Chandler, T. E. Moore, and M. Bouhram (2001b), Plasmaspheric material on highlatitude open field lines, J. Geophys. Res., 106, 6085.

Tsyganenko, N. A. (2002), A Model of the near magnetosphere with a dawn-dusk asymmetry: 1. Mathematical structure, J. Geophys. Res., 107(A8), 1179, doi:10.1029/2001JA000219.

A. J. Coster, P. J. Erickson, and J. C. Foster, MIT Haystack Observatory, Route 40, Westford, MA 01886,USA. (jcf@haystack.mit.edu)

F. J. Rich, Air Force Research Laboratory, 29 Randolph Road, Hanscom Air Force Base, MA 01731-3010, USA.

B. R. Sandel, Lunar and Planetary Laboratory, University of Arizona, 1040 East 4th Street, Room 901, Tucson, AZ 85721, USA. 